\title{
Energy Conversion in Protocells with Natural Nanoconductors
}

\author{
Jian Xu, ${ }^{1}$ T. Kyle Vanderlick, ${ }^{1}$ and David A. LaVan ${ }^{2}$ \\ ${ }^{1}$ School of Engineering and Applied Science, Yale University, New Haven, CT 06511, USA \\ ${ }^{2}$ Material Measurement Laboratory, National Institute of Standards and Technology, Gaithersburg, MD 20899, USA
}

Correspondence should be addressed to David A. LaVan, david.lavan@nist.gov

Received 22 June 2011; Accepted 17 July 2011

Academic Editor: Tebello Nyokong

Copyright ( 92012 Jian Xu et al. This is an open access article distributed under the Creative Commons Attribution License, which permits unrestricted use, distribution, and reproduction in any medium, provided the original work is properly cited.

\begin{abstract}
While much nanotechnology leverages solid-state devices, here we present the analysis of designs for hybrid organic-inorganic biomimetic devices, "protocells," based on assemblies of natural ion channels and ion pumps, "nanoconductors," incorporated into synthetic supported lipid bilayer membranes. These protocells mimic the energy conversion scheme of natural cells and are able to directly output electricity. The electrogenic mechanisms have been analyzed and designs were optimized using numerical models. The parameters that affect the energy conversion are quantified, and limits for device performance have been found using numerical optimization. The electrogenic performance is compared to conventional and emerging technologies and plotted on Ragone charts to allow direct comparisons. The protocell technologies summarized here may be of use for energy conversion where large-scale ion concentration gradients are available (such as the intersection of fresh and salt water sources) or small-scale devices where low power density would be acceptable.
\end{abstract}

\section{Introduction}

Protocells are simplified, synthetic versions of natural cells that can be engineered for specific functions. The protocell designs described here consist of well-characterized molecular components and can be designed to maximize energy conversion $[1,2]$. Our protocell designs are inspired by natural cell structures, but are not a simple duplicate of natural cells. These protocells have one or more lipid bilayers [3-5], membranes of back-to-back monolayers of amphiphilic lipid molecules formed by hydrophobic interactions, with appropriate nanoconductors $[1,6-10]$ to achieve the performance goals. The lipid bilayers would be stabilized, such as on a mesoporous silica [11] or nanofiber support [12]. The nanoconductors incorporated into the membranes can be either natural or engineered [13] membrane proteins, including ion channels and ion pumps [1, 6-10, 14]; they are responsible for the regulation of ionic flux through the lipid bilayer. Channels let ions passively travel along the electrochemical gradient and may be gated to open and close in response to chemical, mechanical, or electrical signals, while pumps actively move ions against the electrochemical gradient but require energy input, for example, from ATP hydrolysis $[15,16]$. Ion transport is widely studied in the context of biology and neuroscience of natural cells $[14,16,17]$. The protocells described here exploit and extend the electrical energy conversion mechanisms found in natural cells by assembling optimized combinations of nanoconductors to maximize energy output.

Emerging energy conversion devices rely on a myriad of technologies, including solid-state materials based on thermoelectric [18-20], piezoelectric [21, 22], and photovoltaic $[23,24]$ effects. Thermoelectric devices convert a thermal gradient into electric voltage; these devices require the unusual combination of good electrical conductivity and poor thermal conductivity, for example, bismuth telluride $\left(\mathrm{Bi}_{2} \mathrm{Te}_{3}\right)$ or its alloys with selenium $[18-20,25,26]$; the energy conversion efficiency of thermoelectric devices is still low $(<10 \%)[18,19]$. Piezoelectric devices convert mechanical strain into charge based on the strain-induced charge separation effect of piezoelectric materials, such as quartz crystals [21, 22] or $\mathrm{ZnO}$ nanowires [27]. However, the energy output of piezoelectric devices is low $\left(\approx 10^{4} \mathrm{~J} \cdot \mathrm{m}^{-3}\right)$ $[28,29]$; these devices can only satisfy applications with very low power consumption $(<\mathrm{mW})[30,31]$. And of course, photovoltaic devices convert light energy into electricity. Single junction thin film photovoltaic devices have energy conversion efficiency up to $\approx 25 \%$ [32-34]. Multijunction 
(a)

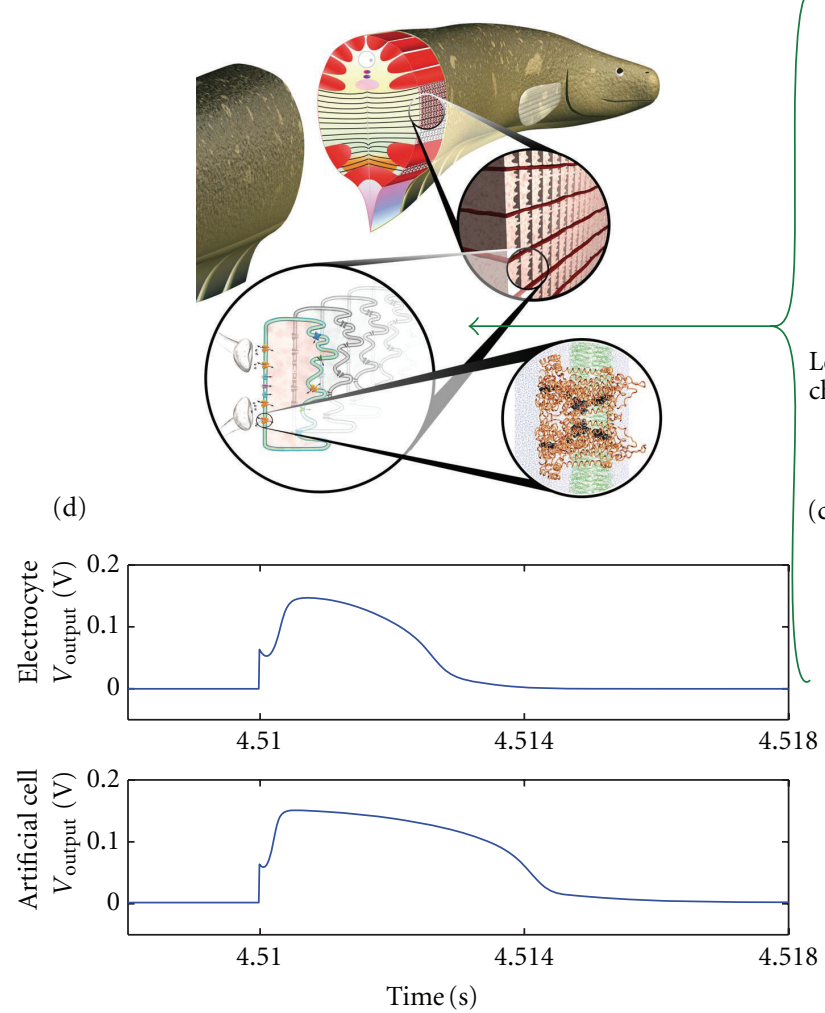

(b)

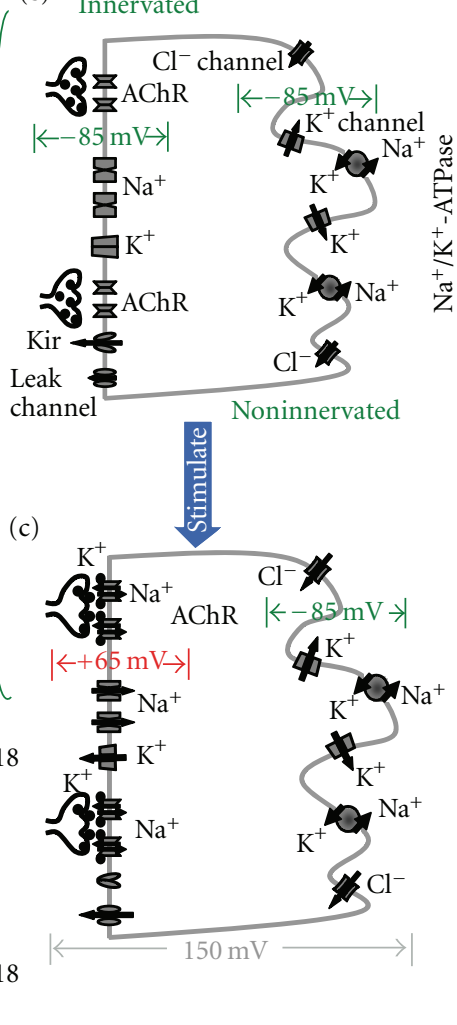

FIGURE 1: The electrogenic mechanism and performance of a protocell with AC output. (a) The anatomy of the electric eel [1]. (b) and (c) The electrocyte in the resting and the stimulated stage [1]. (d) The calculated voltage outputs of the electrocyte and the optimally configured artificial protocell.

inorganic photovoltaic cells convert broader ranges of the available spectrum into electricity; the reported efficiency of multijunction cells has reached $\approx 42 \%[23,24]$.

In contrast to these solid-state materials, individual biological components have significantly higher energy conversion efficiency. For instance, $\mathrm{Na}^{+} / \mathrm{K}^{+}$-ATPase, the ubiquitous ion pump, which maintains transmembrane $\mathrm{Na}^{+}$and $\mathrm{K}^{+}$ gradients, actively pumps $\mathrm{Na}^{+}$and $\mathrm{K}^{+}$against their ion gradients with an efficiency of $75 \%$ to $80 \%$ using energy from ATP hydrolysis $[35,36]$. Another transmembrane protein, $\mathrm{F}_{1}$-ATPase, is reported to convert the free energy from ATP hydrolysis into the rotation of $\mathrm{F}_{1}$ motor with the efficiency close to $100 \%$ [37-40]. However, neither of these numbers takes into account losses in the rest of the ATP energy cycle.

Current biological energy conversion schemes usually rely on the formation of an intermediate product (oil, sugar, ethanol, etc.) that can be refined and burned to produce electricity $[41,42]$ with substantial losses in this step; however, cells also convert chemical energy directly into action potentials, and we have been interested in exploring this "direct to electricity" approach that eliminates the combustion/fuel cell losses. For instance, Electrophorus electricus generates electricity to sense in murky water, stun prey, and ward off predators $[43,44]$. A mature electric eel can generate substantial electric voltage (open circuit) of $400 \mathrm{~V}$ to $600 \mathrm{~V}[8,44,45]$, with current peaks (short circuit) of
$1 \mathrm{~A}[45,46]$. The electricity is produced by the collective behavior of its electrogenic cells, the "electrocytes", under the synchronization of its electromotor neurons $[8,45,47]$ (Figure 1(a)). The electrocyte generates electricity in the form of action potentials; each electrocyte may produce $\approx 150 \mathrm{mV}$ transcellular potential with typical durations on the order of $3 \mathrm{~ms}[8,45]$. Many other natural cells produce action potentials with varying amplitudes and durations. For instance, a squid giant axon generates $\approx 100 \mathrm{mV}$ for $\approx 1 \mathrm{~ms}[17,48-52]$. The electricity is converted from the transmembrane ion gradient through these cell membranes by membrane-protein-regulated ion transport $[8,17,45]$.

Artificial protocells designed to mimic and maximize the energy conversion schemes seen in natural electrogenic cells, are an intriguing approach to energy conversion that builds on recent advances in synthetic biology and nanotechnology.

\section{Electrogenic Mechanism of Protocells}

In the electrocyte, the transmembrane proteins necessary for action potential formation are asymmetrically distributed across two primary membranes (Figure 1(b)) separated by insulating septa $[8,43-45]$. The noninnervated membrane exhibits high densities of $\mathrm{Na}^{+} / \mathrm{K}^{+}$-ATPase pumps, $\mathrm{K}^{+}$channels, and $\mathrm{Cl}^{-}$channels, which maintain a resting potential of $\approx-85 \mathrm{mV}[8,45,53]$. The innervated membrane 
contains high densities of acetylcholine receptors (AChRs) and voltage-gated $\mathrm{Na}^{+}$channels, which are responsible for the activation of the action potential (AP); there are also inward rectifier $\mathrm{K}^{+}$channels (Kirs) [8], voltage-gated $\mathrm{K}^{+}$ channels (Kvs) [9], and leak channels [8] on the innervated membrane.

Upon binding of a chemical agonist, acetylcholine (ACh), the ACh receptors (AChR) become permeable to $\mathrm{Na}^{+}$and $\mathrm{K}^{+}$ cations. The opening of AChRs depolarizes the innervated membrane, raising the open probability of voltage-gated $\mathrm{Na}^{+}$ ion channels (Figure 1(c)) $[6,8,44]$. With positively charged ions $\left(\mathrm{Na}^{+}\right)$flowing into the cell, the innervated membrane potential further increases, which enhances the opening of additional voltage-gated $\mathrm{Na}^{+}$channels. This cascade, where ACh receptors open large number of voltage-gated $\mathrm{Na}^{+}$ channels, results in the formation of an AP on the innervated membrane. The inward rectifier $\mathrm{K}^{+}$channels are closed during this stage, which speeds the increase of the membrane potential. At the peak, the innervated membrane potential is $+65 \mathrm{mV}[8,53]$. Because of the existence of abundant voltage-gated $\mathrm{Na}^{+}$ion channels on the innervated membrane, the electrocyte can also be stimulated electrically, that is, injecting current to depolarize the innervated membrane $[54,55]$.

There are no AChRs or voltage-gated $\mathrm{Na}^{+}$ion channels on the noninnervated membrane of the electrocyte (Figure 1(c)) $[8,45,53]$. Therefore, this membrane is unable to respond to either chemical or electrical stimulus. The noninnervated membrane potential remains $\approx-85 \mathrm{mV}$ due to ATPase, $\mathrm{K}^{+}$channel, and $\mathrm{Cl}^{-}$channel activities $[8,45,53]$. At the peak of an action potential, the innervated membrane reaches $+65 \mathrm{mV}$ transmembrane potential resulting in a total $\approx 150 \mathrm{mV}$ voltage output across each electrocyte (Figure 1(c)) [8, 45, 53]. This transcellular potential is summed with serial connection of multiple electrocytes. For an electric eel to generate $600 \mathrm{~V}$ there must be at least 4000 layers of electrocytes connected in series [53]. In every layer, multiple electrocytes are connected in parallel to increase the current (Figure 1(a)). The insulating septa, composed of dense connective tissues $[44,56]$, separate the innervated membrane and the noninnervated membrane and prevent the electric charge from being short-circuited within the fish (Figure 1(a)).

After the peak of action potential, the innervated membrane is repolarized with the inactivation of $\mathrm{Na}^{+}$channels [6] and the opening of inward rectifier channels and voltagegated $\mathrm{K}$ channels $[8,9]$. The leak ion flux further expedites the restoration of membrane potential to the resting state [57].

During the action potential, substantial ion flux occurs through the open ion channels, which results in a net electric current (electric charge flux) from the innervated membrane to the noninnervated membrane. The necessary ion concentration gradient is sustained by the slow and steady action of ion pumps, $\mathrm{Na}^{+} / \mathrm{K}^{+}$-ATPase, relying on energy from ATP hydrolysis $[35,36,58]$.

A protocell, with the same ion channels/pumps configuration as the natural electrocyte, may imitate the electrogenic mechanism of the natural electric eel. Such a protocell pro- duces the electricity in the form of an action potential, that is, an alternating current (AC) output. The ion gradient in this protocell is created, and can be recharged, by ATP fueled ion pumps, for example, $\mathrm{Na}^{+} / \mathrm{K}^{+}$-ATPase $[35,36$, 58]. If other molecular components were added, such as bacteriorhodopsin and $\mathrm{F}_{\mathrm{o}} \mathrm{F}_{1}$-ATP synthase [59-62], this protocell could be recharged by light energy.

A rechargeable protocell with AC output requires concerted system-level interactions of multiple types of ion channels and at least one type of ion pump [1]. A simplified version, reduced to just one type of ion channel (or channel analogue) would lack the ability to recharge, but would be easier to fabricate and could convert an existing ion concentration gradient into DC current, as shown in Figure 2(a).

One scheme for a protocell with DC output consists of two water droplets with different initial salt concentrations, suspended in an immiscible carrier, such as a mixture of oil and lipid. Because of the hydrophobic interactions, the surface of the water droplet is covered by a monolayer of lipid; when the two water droplets are brought into contact, a lipid bilayer forms at the interface of the two water droplets (as shown in Figure 2(a)) [64-68]. The presence of the bilayer prevents the merging of the two water droplets (Figure 2(b)). If an ion selective channel (or synthetic analogue) is inserted at the interface, ions will flow from the high-concentration droplet to the low-concentration one.

Natural ion channels are not very stable, synthetic channel analogues, such as the $S$. aureus $\alpha$-hemolysin $(\alpha$-HL), are useful platforms to dial-in desired channel performance. The wildtype $\alpha$-HL is normally weakly anion selective $[69,70]$; it can also be made cation selective by protein engineering with or without further chemical modification $[63,71]$; for instance, 2-sulfonatoethyl methanethiosulfonate- (MTSES-) treated G133C mutant has been reported with cation selectivity of $170\left(g_{\mathrm{K}} / g_{\mathrm{Cl}}\right)[63]$.

When cation selective channels are inserted into the bilayer at the interface of two droplets (Figure 2(a)), there will be unbalanced ion transport, which causes charge separation between the droplets. This charge separation results in a potential difference. In addition, due to the different chemical activities of electrodes submerged in the droplets with different concentrations of salts $[72,73]$, the electrode reactions also contribute to the potential difference. The total voltage output of such a system is the combination of contributions from selective ion transport and the electrode reactions in the different solutions. The output can power an external circuit, modeled as a resistor (R), as shown in Figure 2(a).

\section{Electrogenic Performance of Protocells}

Before undertaking the design of an artificial electrocyte, we developed a quantitative model (as described in [1]) to describe the electrogenic mechanism in the natural electrocyte of Electrophorus electricus and to evaluate the influence of molecular parameters on the electrogenic performance of the cell; the numerical model served to guide the design of the protocell to optimize the electrogenic performance. 


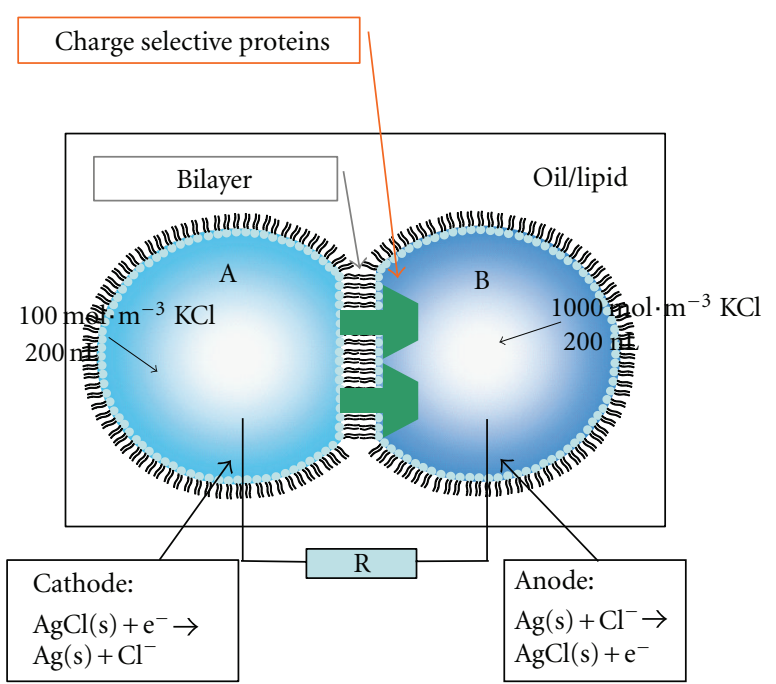

(a)

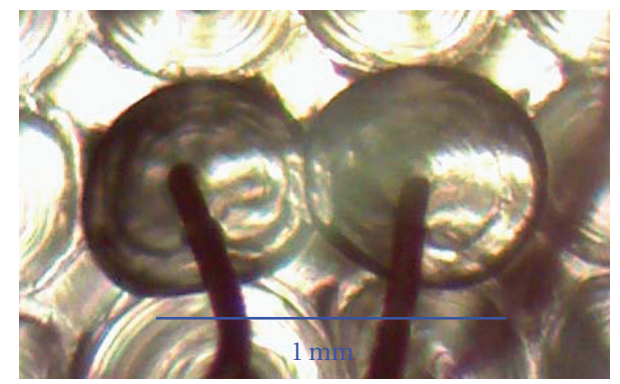

(b)



(c)

FIGURE 2: The electrogenic mechanism and performance of a protocell with DC output. (a) The schematic of this protocell (not drawn to scale) [2]; (b) the microscopic image of the structure of this protocell (scale bar: $1 \mathrm{~mm}$ ); (c) the calculated voltage output of this protocell using a cation-selective channel (MTSES-treated G133C $\alpha$-HL mutant), based on published channel parameters [63]. The total voltage output $\left(E_{t}\right)$ is shown with the contribution from ion transport through the channels $\left(E_{r}\right)$ and contributions from the electrodes $\left(E_{c}\right)$.

To summarize briefly, the ionic current through innervated membrane of the electrocyte (Figure $1(\mathrm{~b})$ ) is described by the Hodgkin-Huxley model [17], with currents through the AChR and Kir channels;

$$
\begin{aligned}
I= & C_{M} \frac{d V}{d t}+\bar{g}_{\mathrm{K}} n^{4}\left(V-V_{\mathrm{K}}\right)+\bar{g}_{\mathrm{Na}} m^{3} h\left(V-V_{\mathrm{Na}}\right) \\
& +\bar{g}_{l}\left(V-V_{l}\right)+I_{\mathrm{Kir}}+I_{\mathrm{AChR}},
\end{aligned}
$$

where $I$ is the current through the innervated membrane, $C_{M}$ is membrane capacitance, and $V$ is the membrane potential. $\bar{g}_{\mathrm{K}}$ is the maximum conductance of voltage-gated $\mathrm{K}^{+}$channel, $n$ determines the open probability of $\mathrm{K}^{+}$channel, $V_{\mathrm{K}}$ is the equilibrium potential of $\mathrm{K}^{+}$ions; $\bar{g}_{\mathrm{Na}}$ and $V_{\mathrm{Na}}$ are those of $\mathrm{Na}^{+}$channels, $m$ controls the activation of $\mathrm{Na}^{+}$ channels, and $h$ determines the inactivation of $\mathrm{Na}^{+}$channels. $\bar{g}_{l}$ is the conductance of leak channel and $V_{l}$ is the potential at which the leak current is zero. $I_{\text {Kir }}$ is the current through the inward rectifier channels. $I_{\mathrm{AChR}}$ is the current through AChR.

There are $\mathrm{K}^{+}$and $\mathrm{Cl}^{-}$ion channels as well as $\mathrm{Na}^{+} / \mathrm{K}^{+}$ATPase on the noninnervated membrane. The ionic current through the ion channel in the noninnervated membrane (Figure 1(b)) is described by the Goldman-Hodgkin-Katz current equation [6], which depicts the current through a channel as a function of membrane potential and the ion gradient. The active transport of ions by $\mathrm{Na}^{+} / \mathrm{K}^{+}$-ATPase on the noninnervated membrane was modelled with MichaelisMenten kinetics at a ratio of three $\mathrm{Na}^{+}$ions per two $\mathrm{K}^{+}$ions $[74,75]$.

The missing physiological parameters were found numerically by matching the model current output to the nuances of the measured action potential curve on the natural electrocyte with nonlinear least squares $[76,77]$.

The voltage output of the natural electrocyte is shown in the upper trace of Figure 1(d). The design of the protocell was numerically optimized to maximize the electrogenic performance. The design of the protocell started as a list of natural nanoconductors (i.e., ion channels/pumps), basic biophysical parameters (ion permeabilities, two insulating membranes, etc.); the objective of the numerical optimization was to maximize the electrogenic performance (e.g., single pulse energy output, power output density, or energy conversion efficiency) of the protocell design.

The electrical energy output of an artificial cell is defined as

$$
W=\int U I d t
$$


where $W$ is the electrical power output and $U$ and $I$ are the voltage and current applied, over time, $t$. The single pulse energy output is defined as the energy output during one firing of the action potential. The power output density is defined as the energy output of a single layer of cells in a unit of time and with a unit area of cell membrane.

The energy conversion efficiency $\Phi$ of the AC protocell is defined as

$$
\Phi=\frac{W_{\text {out }}}{E_{\text {sti }}+E_{\text {ATPase }} / \Phi_{\text {ATP }}},
$$

where $W_{\text {out }}$ is the work done across the external circuit, $E_{\text {sti }}$ is the energy input from the electrical stimuli, $E_{\mathrm{ATP}}$ ase is the energy from ATP hydrolysis of $\mathrm{Na}^{+} / \mathrm{K}^{+}$-ATPase, and $\Phi_{\text {ATP }}$ (around $75 \%$ to $80 \%$ ) [78] is the energy conversion efficiency of ATP biosynthesis by oxidation of glucose or fatty acids. The transmembrane ion concentration gradient of the cell is sustained by $\mathrm{Na}^{+} / \mathrm{K}^{+}$-ATPase. The pumps are fuelled by ATP hydrolysis [58], consuming $5.9 \times 10^{4} \mathrm{~J} / \mathrm{mol}(14 \mathrm{kcal} / \mathrm{mol})$ [79].

The numerical optimization produces a configuration for the protocell that best achieves the design objective. Constrained nonlinear numerical optimization $[76,77]$ was used to guide the design. One of the constraints was to maintain the total channel density on each membrane while the density of individual type of channels was allowed to change in the algorithm. The resulting protocell, optimized for the electrogenic performance, with the same overall channel densities as the natural electrocyte, may produce action potentials that are longer in duration than the natural electrocyte (Figure 1(d)). The protocell design has both higher power output and greater energy conversion efficiency than a natural electrocyte (Table 1). An optimally configured protocell is predicted to produce $0.545 \mathrm{~W} \cdot \mathrm{m}^{-2}$ per cell; the power output density of the protocells would be linearly dependent on the layers of protocells; a protocell array with dimensions $4.3 \mathrm{~mm} \times 4.3 \mathrm{~mm} \times 3.9 \mathrm{~mm}$ could continuously supply $300 \mu \mathrm{W}$ given a sufficient energy source.

The electrogenic performance of the protocell optimized for DC output was also quantitatively analyzed with a numerical model (as described in [2]). In this protocell, the electric potential $\left(E_{t}\right)$ consists of two components (Figure 2(c)): (1) the electric potential $\left(E_{r}\right)$, due to the ion movement through the ion-selective membrane proteins, for example, $\alpha$-HL mutants; (2) the electrode potential $\left(E_{c}\right)$, due to the different activities of the two electrodes in solutions of different ion concentration;

$$
E_{t}=E_{c}+E_{r}
$$

The electrode potential $\left(E_{c}\right)$ is a function of chloride ion concentrations in the two droplets $[72,73]$ :

$$
E_{c}=\frac{R T}{F} \ln \frac{a_{\mathrm{Cl}^{-}}, \text {Anode }}{a_{\mathrm{Cl}^{-}, \text {Cathode }}}=\frac{R T}{F} \ln \frac{\gamma_{B} m_{B}}{\gamma_{A} m_{A}} .
$$

$a_{\mathrm{Cl}^{-}}$, Anode and $a_{\mathrm{Cl}^{-}}$, Cathode are the chemical activities of chloride ions around the two electrodes; $\gamma_{B}$ is the activity coefficient of the ions in the droplet $B ; m_{B}$ is the molality $\left(\mathrm{mol} \cdot \mathrm{kg}^{-1}\right)$ of droplet $B ; \gamma_{A}$ and $m_{A}$ are those for the droplet A. $R$ is the gas constant; $T$ is temperature; $F$ is the Faraday constant.

The potential $E_{r}$, from the unbalanced ion transport through the ion selective $\alpha$-HL mutants, is depicted by a simplified version of Hodgkin-Huxley model [17]:

$$
I=C \frac{d E_{r}}{d t}+g_{\mathrm{K}}\left(E_{r}-V_{\mathrm{K}}\right)+g_{\mathrm{Cl}}\left(E_{r}-V_{\mathrm{Cl}}\right)
$$

$I$ is the current through the lipid bilayer; $C$ is the membrane capacitance; $g_{\mathrm{K}}$ and $g_{\mathrm{Cl}}$ are the $\mathrm{K}^{+}$and $\mathrm{Cl}^{-}$conductance's of the $\alpha$-HL mutants; $V_{\mathrm{K}}$ and $V_{\mathrm{Cl}}$ are the reversal potentials of $\mathrm{K}^{+}$and $\mathrm{Cl}^{-}$ions.

The total voltage output $\left(E_{t}\right)$ of this protocell is coupled electrically by Kirchhoff's laws through the external circuit (Figure 2(a)). As seen in Figure 2(c), the total voltage output $E_{t}$ is the summation of the potential $E_{r}$ due to the unbalanced ion transport and the potential $E_{c}$ due to the chemical activities of electrodes in the different solutions. Over time, $E_{t}$ of the protocell decreases from the initial value, due to the shrinkage of ion gradient through the lipid bilayer, which comes from both the ion exchange through the proteins and the water exchange through the lipid bilayer; in this procedure, the relative droplet sizes may vary over time. The shrinkage of ion gradient causes the decrease of both $E_{r}$ (6) and $E_{c}$ (5). Eventually, the ion concentrations in the two droplets reach equilibrium, which is the end of life of this protocell. During its lifetime, the protocell outputs electricity to power the external circuit (Figure 2(a)); the total energy output density $(w)$ of this protocell is defined as

$$
w=\frac{W}{V}=\frac{\int E_{t} I d t}{V} .
$$

$W$ is the energy output of the protocell; $V\left(\mathrm{~m}^{3}\right)$ is the volume of the protocell.

The energy conversion efficiency is defined as the ratio of the energy output to the free energy stored in the ion concentration gradient. The unitary free energy stored in the concentration gradient, $d \mathrm{G}_{0}\left(\mathrm{~J} \cdot \mathrm{mol}^{-1}\right)$, is given by [15]

$$
d G_{0}=R T \ln \left(\frac{S_{B}}{S_{A}}\right) .
$$

$S_{A}$ and $S_{B}\left(\mathrm{~mol} \cdot \mathrm{L}^{-1}\right)$ are the ion concentrations of the two droplets; $R$ and $T$ are the gas constant and the temperature.

The critical parameters affecting the electrogenic performance (e.g., energy output density, and energy efficiency) are the ion selectivity and channel density (using $\alpha$-HL mutants in the model), the lipid bilayer area, the initial ion concentrations, and the volumes of the two droplets and the external resistance. The design was numerically optimized by varying these device parameters using a constrained nonlinear optimization algorithm [76, 77]. The constraints include the solubility of the ions in the water and the upper limit of channel density in the membrane. The objective function was the total electrogenic performance of the protocell over its lifetime-either the energy density or energy conversion efficiency. The optimization algorithm varies the parameters 
TABLE 1: The calculated electrogenic performance of three cell types: the natural electrocyte, and the optimized protocell with AC output, and the optimized protocell with DC output.

\begin{tabular}{lccc}
\hline Cells & Electrocyte & Optimized AC protocell & DC protocell \\
\hline Maximum power density $\left(\mathrm{W} \cdot \mathrm{kg}^{-1}\right)$ & 3.28 & 4.19 & 12.6 \\
Maximum energy density $\left(\mathrm{W} \cdot \mathrm{h} \cdot \mathrm{kg}^{-1}\right)$ & $3.28^{*}$ & $4.19^{*}$ & 1.92 \\
Maximum energy conversion efficiency $(\%)$ & 14.7 & 19.7 & $48^{\dagger}$ \\
\hline
\end{tabular}

*: The energy densities of these two cells are estimated based on simulations of one hour continuous output; but the actual energy densities may be even larger with enough ATP supplied; Electrophorus electricus can generate low-level action potentials for hours without any sign of exhaustion [80, 81].

$\dagger$ : The protocell designed for DC output can reach an energy conversion efficiency of $48 \%$; but this configuration has impractically low energy density $\left(1.74 \times 10^{3} \mathrm{~J} \cdot \mathrm{m}^{-3}\right.$, i.e., $\left.4.83 \times 10^{-4} \mathrm{~W} \cdot \mathrm{h} \cdot \mathrm{kg}^{-1}\right)$. This protocell designed for maximum energy density $\left(6.9 \times 10^{6} \mathrm{~J} \cdot \mathrm{m}^{-3}\right.$, i.e., $\left.1.92 \mathrm{~W} \cdot \mathrm{h} \cdot \mathrm{kg}^{-1}\right)$ has an energy conversion efficiency of $10 \%$.

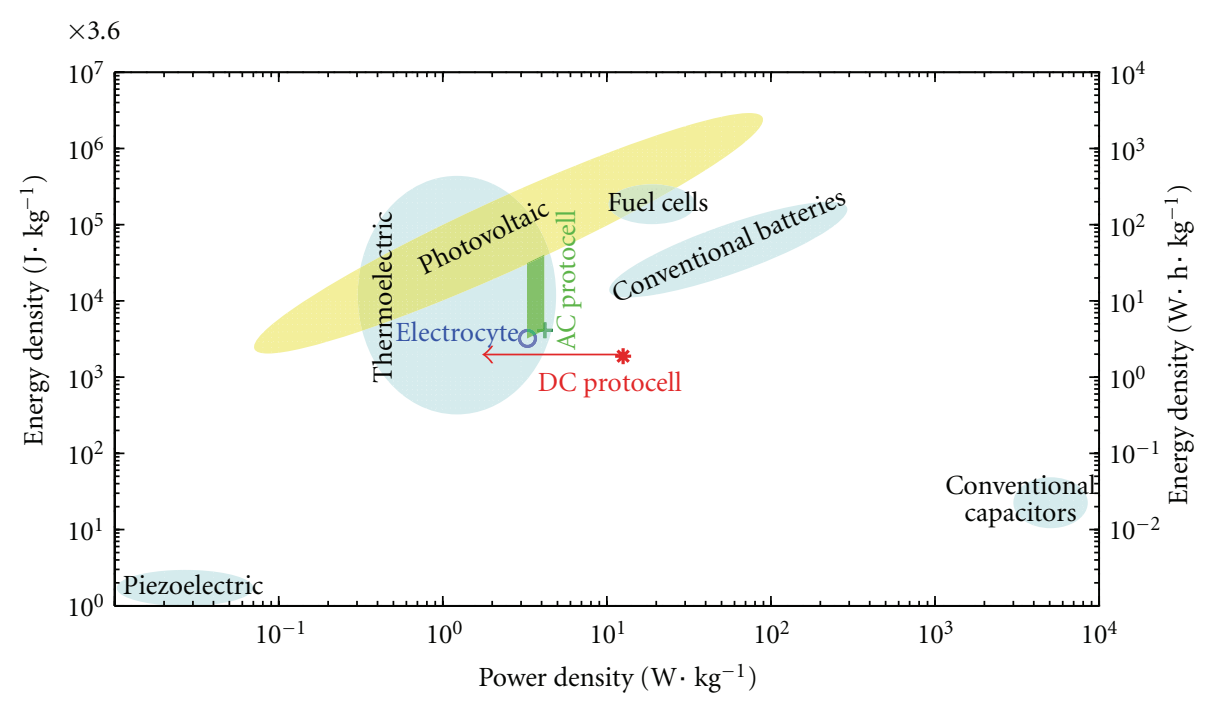

FIGURE 3: Ragone chart comparing the natural electrocyte, AC protocells, and DC protocells with conventional batteries, capacitors, and other energy conversion devices, including piezoelectric, thermoelectric, and photovoltaic devices (data for these other devices from [28, $85,86,88-90]$ ). The AC protocell performance is described by a parallelogram; the bottom edge indicates the performance of AC protocells from initial design parameters (i.e., the natural electrocyte, marked with " $\bigcirc$ ”) to the optimal design parameters (marked with "+") at $1 \mathrm{~h}$ continuous output; the top edge indicates the performance of AC protocells at $10 \mathrm{~h}$ continuous output; the left and right sides reflect the performance of AC protocells spanning from $1 \mathrm{~h}$ to $10 \mathrm{~h}$.

and evaluate the electrogenic performance of the protocell at this set of parameters; the electrogenic performance at this point will be compared to that of the previous set of parameters; based on the comparison results, decisions will be made to either stop the optimization or to further vary the parameters to maximize the electrogenic performance.

The design optimized for maximum energy density output is estimated to produce $6.9 \times 10^{6} \mathrm{~J} \cdot \mathrm{m}^{-3}$ energy $\left(\approx 1.92 \mathrm{~W} \cdot \mathrm{h} \cdot \mathrm{kg}^{-1}\right)$, with an estimated energy conversion efficiency of $10 \%$; the energy density is $\approx 5 \%$ that of a lead-acid battery $[82,83]$. The energy output calculated for a protocell optimally configured for high-energy density $\left(6.92 \times 10^{6} \mathrm{~J} \cdot \mathrm{m}^{-3}\right)$, with two pairs of droplets with diameters $3.9 \mathrm{~cm}$ and $3.3 \mathrm{~cm}$, shows it could power a typical electronic gadget $(\approx 20 \mathrm{~mW})$ for about $10 \mathrm{~h}$.

Higher-energy conversion efficiency can be obtained at the expense of reducing the energy density. The maximum energy conversion efficiency calculated for these protocells reached $48 \%$, but at that point the energy density is quite low $\left(1.74 \times 10^{3} \mathrm{~J} \cdot \mathrm{m}^{-3}\right)$ and not practical for portable applications.
Ragone charts [84-87] compare the performance of electrical energy storage devices, and provide a representation of the energy density related to the speed over which the energy can be delivered (e.g., power density). Conventional batteries and capacitors generally fall towards different ends of a Ragone chart: batteries generally deliver limited power over longer times [84-86]; capacitors generally deliver larger pulses for short times [87]. The Ragone positions of the natural electrocyte, the protocell with AC output and the protocell with DC output are plotted along with other technologies, shown for reference, in Figure 3. The maximum power output of the natural electrocyte (or a protocell with the exact same configuration as the natural electrocyte) is estimated to be $0.427 \mathrm{~W} \cdot \mathrm{m}^{-2} \cdot$ cell $^{-1}$; each cell layer is $130 \mu \mathrm{m}$ wide; if the mass density of the electrocyte is assumed to be $1 \times 10^{3} \mathrm{~kg} \cdot \mathrm{m}^{-3}$ (the major constituent being water), the power density of the natural electrocyte is estimated to be $3.28 \mathrm{~W} \cdot \mathrm{kg}^{-1}$; the power density of the protocell with optimized configuration is estimated to be $4.19 \mathrm{~W} \cdot \mathrm{kg}^{-1}$ (Table 1). Upon stimulus, Electrophorus 
electricus can generate action potentials for hours without any sign of exhaustion through its main organ $[80,81]$; the positions of the natural electrocyte and the AC protocell with optimal design are marked (" $\bigcirc$ " and "+") based on simulation results assuming one-hour continuous energy output, but their actual energy densities may be even higher if enough ATP was available. Therefore, the position of the AC protocell in the Ragone chart is described by a parallelogram; the vertical range indicates the performance of $\mathrm{AC}$ protocell spanning from $1 \mathrm{~h}$ to $10 \mathrm{~h}$ at given design parameters, which designates that the actual energy densities of AC protocells could be even larger than the current estimation with enough ATP; the horizontal range of the parallelogram indicates the range of performance of $\mathrm{AC}$ protocells from initial design parameters to optimal design parameters.

The protocell designed for DC output is estimated to produce $6.9 \times 10^{6} \mathrm{~J} \cdot \mathrm{m}^{-3}$, equivalent to $1.92 \mathrm{~W} \cdot \mathrm{h} \cdot \mathrm{kg}^{-1}$; the average power density is $12.6 \mathrm{~W} \cdot \mathrm{kg}^{-1}$, calculated from the energy density and the lifetime of the protocell (lifetime is limited by the initial concentration and discharge rate in this case). The lifetime scales linearly with the volume; droplets with 10-times larger diameters have 1000-times larger volumes and would have 1000-times longer lifetime but the total energy density available for output would remain the same at $1.92 \mathrm{~W} \cdot \mathrm{h} \cdot \mathrm{kg}^{-1}$. Therefore, the position of the protocell with DC output in the Ragone chart is depicted by a star $(*)$ with dotted lines, indicating that depending on the droplet sizes, the same energy density may be delivered more slowly and at lower power density than the results based on a configuration calculated with droplets of $254 \mathrm{~nL}$ and $146 \mathrm{~nL}$. The energy density of the DC protocell is $\approx 5 \%$ that of a lead-acid battery $[82,83]$; the power density of the DC protocell is comparable to traditional batteries. Compared with other alternative energy conversion devices (Figure 3), the electrogenic performance of protocells is much better than that of the piezoelectric devices and comparable to that of thermoelectric and photovoltaic devices. The photovoltaic devices have dramatically worse performance (e.g., the power density of $\approx 10 \mu \mathrm{W} \cdot \mathrm{cm}^{-2}$ ) when used indoors than outdoors (power density of $\approx 1.5 \times 10^{4} \mu \mathrm{W} \cdot \mathrm{cm}^{-2}$ ); when compared to the indoor performance, the protocells have larger power density than the photovoltaic devices. In addition, the AC protocell can be recharged using a biological energy source, for example, ATP, which seems appealing for powering implantable devices.

The protocell technologies summarized here may be of use for energy conversion where large-scale ion concentration gradients are available (such as the intersection of fresh and salt water sources) and for those applications where low power density is not a limiting factor.

\section{Conclusion}

Protocells, by assembling natural and synthetic nanoscale conductors (e.g., ion channels/pumps), provide a new approach to convert chemical energy (or energy stored in a concentration gradient) into electricity. The electrogenic performance of these protocells has been numerically modeled and effectively enhanced by optimization. The optimized designs produce energy densities sufficiently large for practical applications, from low-power consumer electronics to implantable biomedical devices.

The challenges to this technology lay in creating stable and selective channels and ion pumps-natural membrane proteins are currently purified and inserted into lipid bilayers [91, 92]. Synthetic counterparts of ion channels can be synthesized by protein engineering, such as $\alpha$-hemolysin and its mutants [63, 71]. Artificial ion channels may also be fabricated by precisely tailoring the radii of $\mathrm{SiO}_{2}$ nanopores through organic group functionalization $[93,94]$. Of course, long-term stability is another concern-the droplet bilayer is one approach, which has been reported to extend bilayer lifetimes [64-68]. Other approaches for stabilizing the lipid bilayer include mesoporous silica [11] or nanofiber support [12]; these porous supports not only stabilize the lipid bilayer but also maintain water accessibility to both sides of the bilayer [12], which is critical for device function. As is done with conventional batteries, multiple protocells could be connected in series and/or parallel to achieve needed voltage and current outputs.

\section{Acknowledgments}

This paper was supported in part by the National Institutes of Health through the NIH Roadmap for Medical Research, as part of the National Center for Design of Biomimetic Nanoconductors, award number PHS 2 PN2 EY016570B. The full description of the materials and software used in this paper requires the identification of certain products, materials, and software suppliers. The inclusion of such information should in no way be construed as indicating that such products, materials, or software are endorsed by NIST or are recommended by NIST or that they are necessarily the best products, materials, or software for the purposes described.

\section{References}

[1] J. Xu and D. A. Lavan, "Designing artificial cells to harness the biological ion concentration gradient," Nature Nanotechnology, vol. 3, no. 11, pp. 666-670, 2008.

[2] J. Xu, F. J. Sigworth, and D. A. Lavan, "Synthetic protocells to mimic and test cell function," Advanced Materials, vol. 22, no. 1, pp. 120-127, 2010.

[3] W. Hanke and W. Schlue, Planar Lipid Bilayers: Methods and Applications, Academic Press, San Diego, Calif, USA, 1993.

[4] D. Gallez, N. M. C. Pinto, and P. M. Bisch, "Nonlinear dynamics and rupture of lipid bilayers," Journal of Colloid And Interface Science, vol. 160, no. 1, pp. 141-148, 1993.

[5] P. F. Fahey, D. E. Koppel, L. S. Barak et al., "Lateral diffusion in planar lipid bilayers," Science, vol. 195, no. 4275, pp. 305-306, 1977.

[6] B. Hille, Ion Channels of Excitable Membranes, Sinauer Associates, Sunderland, Mass, USA, 3rd edition, 2001.

[7] C. M. Armstrong, "Inactivation of the sodium channel. II. Gating current experiments," Journal of General Physiology, vol. 70 , no. 5, pp. 567-590, 1977.

[8] A. Gotter, M. Kaetzel, and J. Dedman, "Electrophorus electricus as a model system for the study of membrane excitability," Comparative Biochemistry and Physiology A, vol. 119, no. 1, pp. 225-241, 1998. 
[9] W. B. Thornhill, I. Watanabe, J. J. Sutachan et al., "Molecular cloning and expression of a Kv1.1-like potassium channel from the electric organ of Electrophorus electricus," Journal of Membrane Biology, vol. 196, no. 1, pp. 1-8, 2003.

[10] F. H. Yu and W. A. Catterall, "Overview of the voltage-gated sodium channel family," Genome Biology, vol. 4, no. 3, article no. 207, 2003.

[11] J. Brinker, Y. Lu, A. Sellinger, and H. Fan, "Evaporationinduced self-assembly: nanostructures made easy," Advanced Materials, vol. 11, no. 7, pp. 579-585, 1999.

[12] F. Yi, J. Xu, A. M. Smith, A. N. Parikh, and D. A. Lavan, "Nanofiber-supported phospholipid bilayers," Soft Matter, vol. 5, no. 24, pp. 5037-5041, 2009.

[13] J. J. Kasianowicz, D. L. Burden, L. C. Han, S. Cheley, and H. Bayley, "Genetically engineered metal ion binding sites on the outside of a channel's transmembrane $\beta$-barrel," Biophysical Journal, vol. 76, no. 2, pp. 837-845, 1999.

[14] C. Armstrong and B. Hille, "Voltage-gated ion channels and electrical excitability," Neuron, vol. 20, no. 3, pp. 371-380, 1998.

[15] J. Berg, J. Tymoczko, and L. Stryer, Biochemistry, W. H. Freeman and Company, New York, NY, USA, 2001.

[16] I. Levitan and L. Kaczmarek, The Neuron, Oxford University Press, New York, NY, USA, 2002.

[17] A. Hodgkin and A. F. Huxley, "A quantitative description of membrane current and its application to conduction and excitation in nerve," The Journal of Physiology, vol. 117, no. 4, pp. 500-544, 1952.

[18] L. E. Bell, "Cooling, heating, generating power, and recovering waste heat with thermoelectric systems," Science, vol. 321, no. 5895, pp. 1457-1461, 2008.

[19] S. B. Riffat and X. Ma, "Thermoelectrics: a review of present and potential applications," Applied Thermal Engineering, vol. 23, no. 8, pp. 913-935, 2003.

[20] T. Cole, "Thermoelectric energy conversion with solid electrolytes," Science, vol. 221, no. 4614, pp. 915-920, 1983.

[21] R. L. Bunde, E. J. Jarvi, and J. J. Rosentreter, "Piezoelectric quartz crystal biosensors," Talanta, vol. 46, no. 6, pp. 12231236, 1998.

[22] Y. S. Fung and Y. Y. Wong, "Self-assembled monolayers as the coating in a quartz piezoelectric crystal immunosensor to detect Salmonella in aqueous solution," Analytical Chemistry, vol. 73, no. 21, pp. 5302-5309, 2001.

[23] R. R. King, D. C. Law, K. M. Edmondson et al., " $40 \%$ efficient metamorphic GaInP/GaInAs/Ge multijunction solar cells," Applied Physics Letters, vol. 90, no. 18, Article ID 183516, 3 pages, 2007.

[24] A. Barnett, D. Kirkpatrick, C. Honsberg et al., "Very high efficiency solar cell modules," Progress in Photovoltaics: Research and Applications, vol. 17, no. 1, pp. 75-83, 2008.

[25] S. A. Sapp, B. B. Lakshmi, and C. R. Martin, "Template synthesis of bismuth telluride nano wires," Advanced Materials, vol. 11, no. 5, pp. 402-404, 1999.

[26] O. Yamashita, S. Tomiyoshi, and K. Makita, "Bismuth telluride compounds with high thermoelectric figures of merit," Journal of Applied Physics, vol. 93, no. 1, pp. 368-374, 2003.

[27] R. Yang, Y. Qin, L. Dai, and Z. L. Wang, "Power generation with laterally packaged piezoelectric fine wires," Nature Nanotechnology, vol. 4, no. 1, pp. 34-39, 2008.

[28] S. Roundy, E. S. Leland, J. Baker et al., "Improving power output for vibration-based energy scavengers," IEEE Pervasive Computing, vol. 4, no. 1, pp. 28-36, 2005.
[29] S. Roundy, P. K. Wright, and J. M. Rabaey, Energy Scavenging for Wireless Sensor Networks: With Special Focus on Vibrations, Springer, New York, NY, USA, 2004.

[30] J. A. Paradiso and T. Starner, "Energy scavenging for mobile and wireless electronics," IEEE Pervasive Computing, vol. 4, no. 1, pp. 18-27, 2005.

[31] A. Iino, K. Suzuki, M. Kasuga, M. Suzuki, and T. Yamanaka, "Development of a self-oscillating ultrasonic micro-motor and its application to a watch," Ultrasonics, vol. 38, no. 1-8, pp. 54-59, 2000.

[32] K. Ramanathan, M. A. Contreras, C. L. Perkins et al., "Properties of $19.2 \%$ efficiency $\mathrm{ZnO} / \mathrm{CdS} / \mathrm{CuInGaSe}{ }_{2}$ thinfilm solar cells this article is a US Government work and is in the public domain in the USA," Progress in Photovoltaics: Research and Applications, vol. 11, no. 4, pp. 225-230, 2003.

[33] P. Liska, K. R. Thampi, M. Gratzel et al., "Nanocrystalline dye-sensitized solar cell/copper indium gallium selenide thinfilm tandem showing greater than 15\% conversion efficiency," Applied Physics Letters, vol. 88, Article ID 203103, 3 pages, 2006.

[34] G. J. Bauhuis, P. Mulder, J. J. Schermer, E. J. HaverKamp, J. van Deelen, and P. K. Larsen, "High efficiency thin film GaAs solar cells with improved radiation hardness," in Proceedings of the 20th European Photovoltaic Solar Energy Conference, pp. 468-471, Barcelona, Spain, June 2005.

[35] J. C. Skou, “The identification of the sodium pump," Bioscience Reports, vol. 18, no. 4, pp. 155-169, 1998.

[36] F. Cornelius, "The sodium pump," in ATPases (Biomembranes A Multi-Volume Treatise), A. G. Lee, Ed., p. 133, JAI Press, London, UK, 1996.

[37] J. K. Lanyi and A. Pohorille, "Proton pumps: mechanism of action and applications," Trends in Biotechnology, vol. 19, no. 4, pp. 140-144, 2001.

[38] H. Noji, R. Yasuda, M. Yoshida, and K. Kinosita, "Direct observation of the rotation of F1-ATPase," Nature, vol. 386, pp. 299-302, 1997.

[39] T. Elston, H. Wang, and G. Oster, "Energy transduction in ATP synthase," Nature, vol. 391, pp. 510-513, 1998.

[40] W. Junge, H. Sielaff, and S. Engelbrecht, "Torque generation and elastic power transmission in the rotary FOF1-ATPase," Nature, vol. 459, pp. 364-370, 2009.

[41] R. M. Allen and H. P. Bennetto, "Microbial fuel-cells," Applied Biochemistry and Biotechnology, vol. 39, no. 1, pp. 27-40, 1993.

[42] K. Rabaey and W. Verstraete, "Microbial fuel cells: novel biotechnology for energy generation," Trends in Biotechnology, vol. 23, no. 6, pp. 291-298, 2005.

[43] R. D. Machado, W. D. Souza, G. Cotta Pereira, and G. D. O. Castro, "On the fine structure of the electrocyte of Electrophorus electricus L," Cell and Tissue Research, vol. 174, no. 3, pp. 355-366, 1976.

[44] C. Mermelstein, M. Costa, and V. Neto, "The cytoskeleton of the electric tissue of Electrophorus electricus, L," Anais da Academia Brasileira de Ciencias, vol. 72, no. 3, pp. 341-351, 2000.

[45] M. Altamirano, "Electrical properties of the innervated membrane of the electroplax of electric eel," Journal of cellular physiology, vol. 46, no. 2, pp. 249-277, 1955.

[46] R. T. Cox, C. W. Coates, and M. V. Brown, "Electric tissuerelations between the structure, electrical characteristics, and chemical processes of electric tissue," Journal of General Physiology, vol. 28, no. 3, pp. 187-212, 1945.

[47] W. S. Hoar, Fish Physiology: Sensory Systems and Electric Organs, Academic Press, New York, NY, USA, 1971. 
[48] A. Hodgkin and A. Huxley, "Measurement of current-voltage relations in the membrane of the giant axon of Loligo," The Journal of Physiology, vol. 116, no. 4, pp. 424-448, 1952.

[49] A. Hodgkin and A. Huxley, "Currents carried by sodium and potassium ions through the membrane of the giant axon of Loligo," Journal of Physiology, vol. 116, no. 4, pp. 449-472, 1952.

[50] A. Hodgkin and A. Huxley, "The components of membrane conductance in the giant axon of Loligo," The Journal of Physiology, vol. 116, no. 4, pp. 473-496, 1952.

[51] A. Hodgkin and A. Huxley, "The dual effect of membrane potential on sodium conductance in the giant axon of Loligo," Journal of Physiology, vol. 116, no. 4, pp. 497-506, 1952.

[52] A. L. Hodgkin and B. Katz, "The effect of temperature on the electrical activity of the giant axon of the squid," The Journal of Physiology, vol. 108, no. 1, p. 37, 1949.

[53] R. Keynes and H. Ferreira, "Membrane potentials in the electroplates of the electric eel," Journal of Physiology, vol. 119, pp. 315-351, 1953.

[54] S. Shenkel and F. Bezanilla, "Patch recordings from the electrocytes of electrophorus: Na channel gating currents," Journal of General Physiology, vol. 98, no. 3, pp. 465-478, 1991.

[55] H. A. Lester, J. P. Changeux, and R. E. Sheridan, "Conductance increases produced by bath application of cholinergic agonists to Electrophorus electroplaques," Journal of General Physiology, vol. 65, no. 6, pp. 797-816, 1975.

[56] M. L. S. Souza, C. F. Freitas, M. A. O. Domingos et al., "Identification and distribution of chondroitin sulfate in the three electric organs of the electric eel, Electrophorus electricus (L.)," Comparative Biochemistry and Physiology B, vol. 146, no. 2, pp. 227-233, 2007.

[57] Y. Nakamura, S. Nakajima, and H. Grundfest, "Analysis of spike electrogenesis and depolarizing $\mathrm{K}$ inactivation in electroplaques of Electrophorus electricus, L," The Journal of General Physiology, vol. 49, no. 2, p. 321, 1965.

[58] C. Tanford, "Equilibrium state of ATP-driven ion pumps in relation to physiological ion concentration gradients," Journal of General Physiology, vol. 77, no. 2, pp. 223-229, 1981.

[59] H. J. Choi and C. D. Montemagno, "Artificial organelle: ATP synthesis from cellular mimetic polymersomes," Nano Letters, vol. 5, no. 12, pp. 2538-2542, 2005.

[60] D. Bald, T. Amano, E. Muneyuki et al., "ATP synthesis by F0F1ATP synthase independent of noncatalytic nucleotide binding sites and insensitive to azide inhibition," Journal of Biological Chemistry, vol. 273, no. 2, pp. 865-870, 1998.

[61] B. Pitard, P. Richard, M. Dunach, and J. L. Rigaud, "ATP synthesis by the $\mathrm{F}_{0} \mathrm{~F}_{1}$ ATP synthase from thermophilic Bacillus PS3 reconstituted into liposomes with bacteriorhodopsin 2 . Relationships between proton motive force and ATP synthesis," European Journal of Biochemistry, vol. 235, no. 3, pp. 779788, 1996.

[62] B. Pitard, P. Richard, M. Dunach, G. Girault, and J. L. Rigaud, "ATP synthesis by the $\mathrm{F}_{0} \mathrm{~F}_{1}$ ATP synthase from thermophilic Bacillus PS3 reconstituted into liposomes with bacteriorhodopsin 1. Factors defining the optimal reconstitution of ATP synthases with bacteriorhodopsin," European Journal of Biochemistry, vol. 235, no. 3, pp. 769-778, 1996.

[63] P. G. Merzlyak, M. F. P. Capistrano, A. Valeva, J. J. Kasianowicz, and O. V. Krasilnikov, "Conductance and ion selectivity of a mesoscopic protein nanopore probed with cysteine scanning mutagenesis," Biophysical Journal, vol. 89, no. 5, pp. 30593070, 2005.

[64] M. A. Holden, D. Needham, and H. Bayley, "Functional bionetworks from nanoliter water droplets," Journal of the
American Chemical Society, vol. 129, no. 27, pp. 8650-8655, 2007.

[65] W. L. Hwang, M. A. Holden, S. White, and H. Bayley, "Electrical behavior of droplet interface bilayer networks: experimental analysis and modeling," Journal of the American Chemical Society, vol. 129, no. 38, pp. 11854-11864, 2007.

[66] M. A. Creasy and D. J. Leo, "Droplet interface bilayer characteristics formed over a synthetic porous substrate," in Proceedings of The International Society for Optical Engineering (SPIE '09), vol. 7291, Nanosensors, Biosensors, and Info-Tech Sensors and Systems, March 2009.

[67] S. A. Sarles and D. J. Leo, "Regulated attachment method for reconstituting lipid bilayers of prescribed size within flexible substrates," Analytical Chemistry, vol. 82, no. 3, pp. 959-966, 2010.

[68] S. A. Sarles and D. J. Leo, "Physical encapsulation of droplet interface bilayers for durable, portable biomolecular networks," Lab on a Chip, vol. 10, no. 6, pp. 710-717, 2010.

[69] L.-Q. Gu and H. Bayley, "Interaction of the noncovalent molecular adapter, $\beta$-cyclodextrin, with the staphylococcal $\alpha$ hemolysin pore," Biophysical Journal, vol. 79, no. 4, pp. 19671975, 2000.

[70] S. A. Glazier, D. J. Vanderah, A. L. Plant, H. Bayley, G. Valincius, and J. J. Kasianowicz, "Reconstitution of the poreforming toxin $\alpha$-hemolysin in phospholipid/18-octadecyl-1thiahexa(ethylene oxide) and phospholipid/n-octadecanethiol supported bilayer membranes," Langmuir, vol. 16, no. 26, pp. 10428-10435, 2000.

[71] S. Y. Noskov, W. Im, and B. Roux, "Ion permeation through the $\alpha$-hemolysin channel: theoretical studies based on Brownian dynamics and Poisson-Nernst-Plank electrodiffusion theory," Biophysical Journal, vol. 87, no. 4, pp. 2299-2309, 2004.

[72] W. J. Hamer and Y. C. Wu, "Osmotic coefficients and mean activity coefficients of uni-univalent electrolytes in water at 25 C," Journal of Physical and Chemical Reference Data, vol. 1, no. 4, pp. 1047-1075, 1972.

[73] E. Amado G and L. H. Blanco, "Osmotic and activity coefficients of aqueous solutions of $\mathrm{KCl}$ at temperatures of 283.15, 288.15, 293.15 and $298.15 \mathrm{~K}$ : a new isopiestic apparatus," Fluid Phase Equilibria, vol. 226, no. 1-2, pp. 261-265, 2004.

[74] J. Novotny and E. Jakobsson, "Computational studies of ionwater flux coupling in the airway epithelium. I. Construction of model," American Journal of Physiology, vol. 270, no. 6, pp. C1751-C1763, 1996.

[75] J. Novotny and E. Jakobsson, "Computational studies of ionwater flux coupling in the airway epithelium. II. Role of specific transport mechanisms," American Journal of Physiology, vol. 270, no. 6, pp. C1764-C1772, 1996.

[76] J. More, "The Levenberg-Marquardt algorithm: implementation and theory," Numerical Analysis, vol. 630, pp. 105-116, 1978.

[77] T. S. Ahearn, R. T. Staff, T. W. Redpath, and S. I. K. Semple, "The use of the Levenberg-Marquardt curve-fitting algorithm in pharmacokinetic modelling of DCE-MRI data," Physics in Medicine and Biology, vol. 50, no. 9, pp. N85-N92, 2005.

[78] H. Kammermeier, "Efficiency of energy conversion from metabolic substrates to ATP and mechanical and chemiosmotic energy," Basic Research in Cardiology, vol. 88, supplement 2, pp. 15-20, 1993.

[79] P. C. Caldwell and H. Schirmer, "The free energy available to the sodium pump of squid giant axons and changes in the sodium efflux on removal of the extracellular potassium," Journal of Physiology, vol. 181, pp. 25P-26P, 1965. 
[80] J. S. Nelson, Fishes of the World, Wiley, 2006.

[81] P. Moller, Electric Fishes: History and Behavior, Chapman \& Hall, London, UK, 1995.

[82] B. Hariprakash, A. U. Mane, S. K. Martha, S. A. Gaffoor, S. A. Shivashankar, and A. K. Shukla, "A low-cost, high energy-density lead/acid battery," Electrochemical and SolidState Letters, vol. 7, no. 3, pp. A66-A69, 2004.

[83] T. Juergens and R. F. Nelson, "A new high-rate, fast-charge lead/acid battery," Journal of Power Sources, vol. 53, no. 2, pp. 201-205, 1995.

[84] G. Delille and B. Francois, "A review of some technical and economic features of energy storage technologies for distribution system integration," in Proceedings of the Electrical Machines, Drives and Power Systems (ELMA '08), pp. 67-72, 2008.

[85] J. M. Miller, "Energy storage technology markets and application's: ultracapacitors in combination with lithium-ion," in Proceedings of the 7th Internatonal Conference on Power Electronics (ICPE '07), pp. 16-22, October 2007.

[86] P. Van den Bossche, F. Vergels, J. Van Mierlo, J. Matheys, and W. Van Autenboer, "SUBAT: an assessment of sustainable battery technology," Journal of Power Sources, vol. 162, no. 2, pp. 913-919, 2006.

[87] J. M. Miller and R. Smith, "Ultra-capacitor assisted electric drives for transportation," in Proceedings of the IEEE International Electric Machines and Drives Conference, vol. 2, pp. 670 676, June 2003.

[88] C. Knight, J. Davidson, and S. Behrens, "Energy options for wireless sensor nodes," Sensors, vol. 8, no. 12, pp. 8037-8066, 2008.

[89] K. Yoshida, S. Tanaka, S. Tomonari, D. Satoh, and M. Esashi, "High-energy density miniature thermoelectric generator using catalytic combustion," Journal of Microelectromechanical Systems, vol. 15, no. 1, pp. 195-203, 2006.

[90] G. L. Bennett, "Space nuclear power: opening the final frontier," in Proceedings of the 4th International Energy Conversion Engineering Conference and Exhibit, San Diego, Calif, USA, 2006.

[91] E. Recio-Pinto, D. Duch, S. Levinson, and B. W. Urban, "Purified and unpurified sodium channels from eel electroplax in planar lipid bilayers," Journal of General Physiology, vol. 90, no. 3, pp. 375-395, 1987.

[92] S. Shenkel, E. C. Cooper, W. James, W. Agnew, and F. Sigworth, "Purified, modified eel sodium channels are active in planar bilayers in the absence of activating neurotoxins," Proceedings of the National Academy of Sciences of the United States of America, vol. 86, no. 23, pp. 9592-9596, 1989.

[93] Y.-B. Jiang, G. Xomeritakis, Z. Chen et al., "Sub-10 nm thick microporous membranes made by plasma-defined atomic layer deposition of a bridged silsesquioxane precursor," Journal of the American Chemical Society, vol. 129, no. 50, pp. 1544615447, 2007.

[94] N. Liu, R. A. Assink, and C. J. Brinker, "Synthesis and characterization of highly ordered mesoporous thin films with$\mathrm{COOH}$ terminated pore surfaces," Chemical Communications, vol. 9, no. 3, pp. 370-371, 2003. 


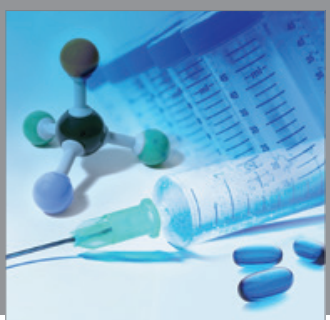

International Journal of

Medicinal Chemistry



Carbohydrate Chemistry

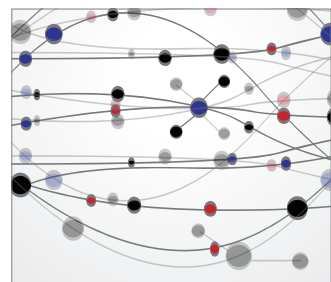

The Scientific World Journal
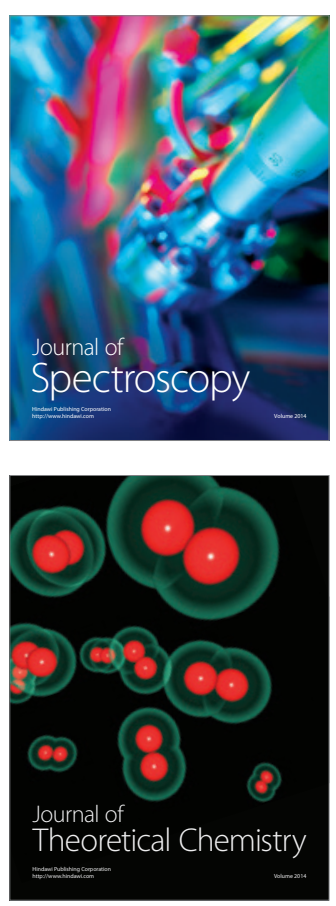
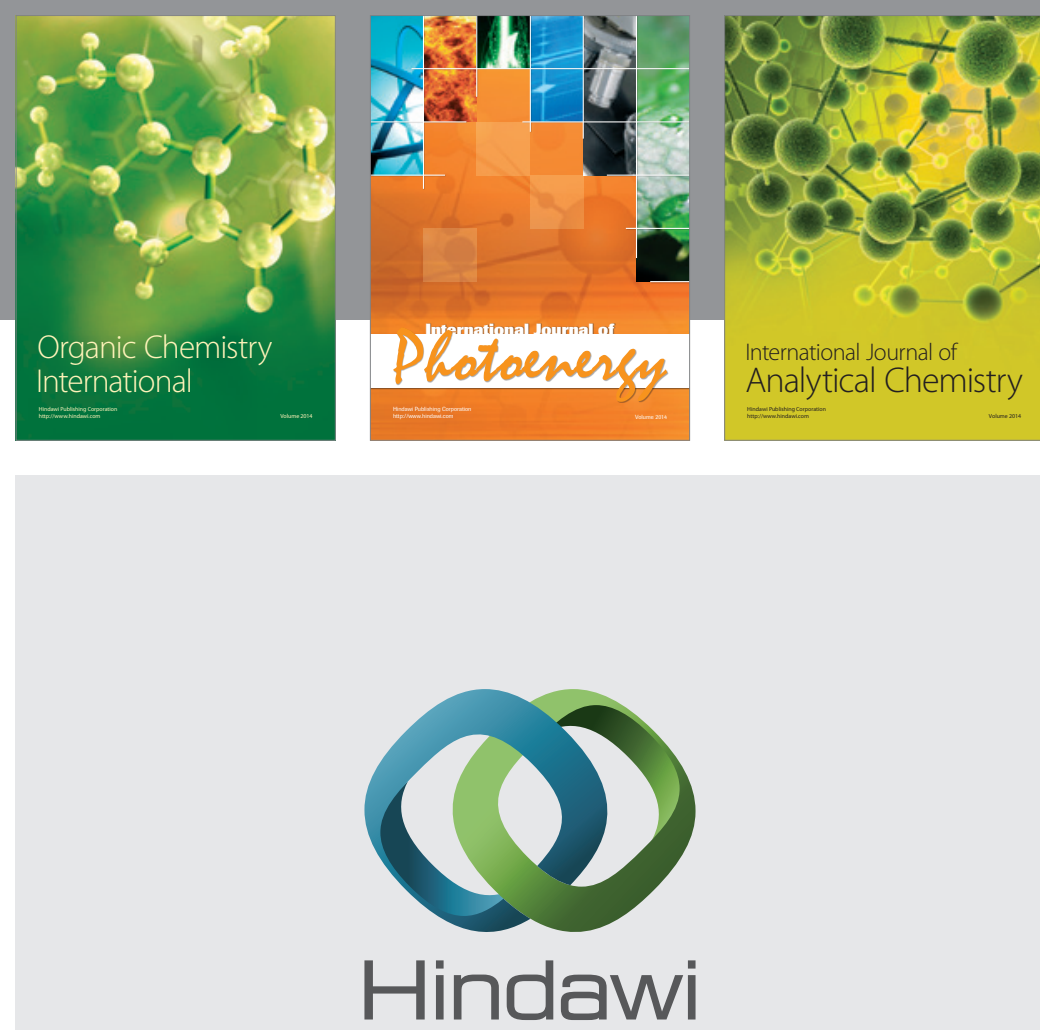

Submit your manuscripts at

http://www.hindawi.com
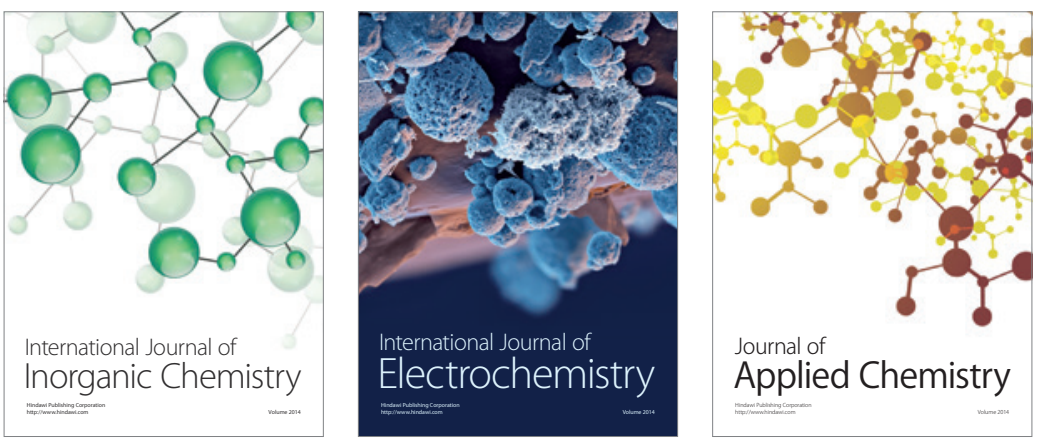

Journal of

Applied Chemistry
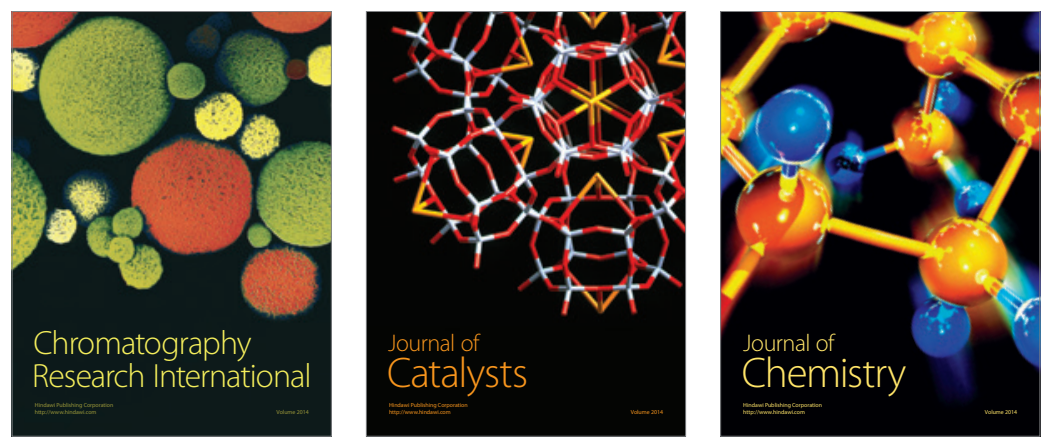
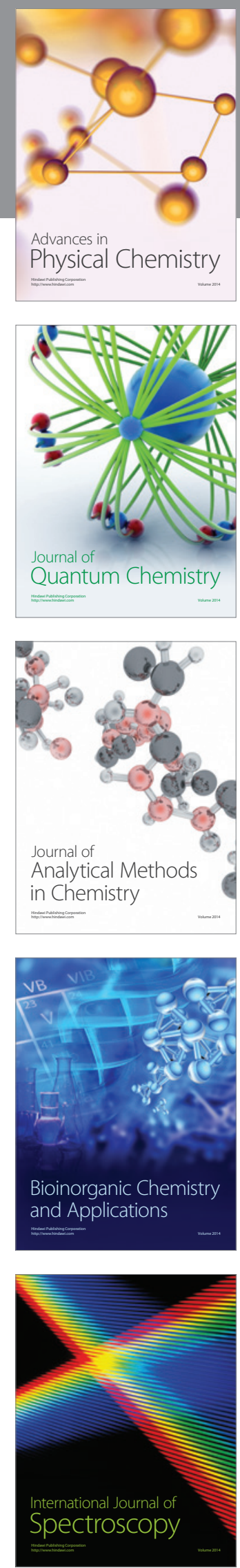